Artigo de Reflexáo/Ensaio

\title{
Infâncias, crianças e travessias: em que barcos navegamos?
}

\section{Childhood, children, and pandemic: in which boat do we sail?}

\author{
Marina Di Napoli Pastore ${ }^{\mathrm{a}}$ (D) \\ anstituto Superior de Ciências da Saúde - ISCISA, Maputo, Moçambique.
}

Como citar: Pastore, M. D. N. (2021). Infâncias, crianças e travessias: em que barcos navegamos?. Cadernos Brasileiros de Terapia Ocupacional, 29, e2797. https://doi.org/10.1590/2526-8910.ctoEN2116

\begin{abstract}
Resumo
O ano de 2020 foi marcado por um cenário mundial em que a pandemia da Covid19 e suas consequências trouxeram diversas questóes sociais à tona, envolvendo a desigualdade social, a invisibilidade e o silenciamento de parcela significativa da população, tal como a amplitude de suas potências, principalmente no que tange à vida das crianças. O diálogo sobre a pluralidade das infâncias e das crianças, bem como das vulnerabilidades e dos modos de agir frente à Covid-19, tem permeado diversas discussóes em disciplinas diversas, nas quais a terapia ocupacional também tem se inteirado, ainda que de maneira inicial, mas com pouca discussão em torno das crianças. Neste sentido e a partir desta constataçáo, este artigo apresenta uma discussão sobre o lugar das crianças no cenário da pandemia, com base em reflexôes teóricas que trazem para o cerne do debate questóes relacionadas à invisibilidade das crianças e seus contextos, as quais, com a situação atual, tornaram-se mais evidentes. Enquanto consideraçóes finais, este texto pretende favorecer um espaço de construção de diálogo e de indagaçôes sobre as açôes dos terapeutas ocupacionais frente às infâncias e crianças, ancorado na pandemia de Covid-19, possibilitando a construção de práticas e açôes contextualizadas e transformadoras.
\end{abstract}

Palavras-chave: Criança, Pandemias, Covid-19, Terapia Ocupacional.

\section{$\underline{\text { Abstract }}$}

The year 2020 has been marked by a world scenario in which the Covid-19 pandemic and its consequences brought several social issues to the fore, involving social inequality, invisibility, and the silencing of a significant portion of the population, such as the breadth of its powers, especially concerning children's lives. The dialogue on the plurality of childhood and children, as well as the vulnerabilities and ways of acting in the face of Covid-19, has permeated several discussions in different disciplines, in which occupational therapy has also been learned, albeit in an initial way, but with little discussion in children's turns. In this sense and from this observation, this article presents a discussion about the place of children in the pandemic scenario, from theoretical reflections that bring to the heart of the debate 
issues related to the invisibility of children and their contexts that, with the current situation, became more evident. As final considerations, this text intends to favor a space for the construction of dialogue and questions about the actions of occupational therapists towards childhood and children, anchored in the Covid-19 pandemic, enabling the construction of contextualized and transformative practices and actions.

Keywords: Child, Pandemics, Covid-19, Occupational Therapy.

\section{Introduçáo}

E as zonas de invisibilidade poderão multiplicar-se em muitas outras regióes do mundo, e talvez mesmo aqui, bem perto de cada um de nós. Talvez baste abrir a janela

(Santos, 2020, p. 8-9).

A situação atual da pandemia ocasionada pelo coronavírus, ou Covid-19, enquanto realidade social existente, enuncia noçôes importantes para o debate, como as concepçôes dos conceitos e normas voltados aos termos do comum e de exceção, de normalidade, de saúde-doença, da verdade e dos óbvios seletivos. Seletivos, nomeados aqui, com base em um entendimento que há um recorte de classe, raça, gênero e geração, do qual as crianças não são, em sua maior parte, consideradas. Muito tem se colocado como o retorno das crianças no pós-pandemia, principalmente temas relacionados às questôes escolares e às situaçóes que estão por vir, enquanto pouco se considera sobre as crianças enquanto sujeitos deste tempo presente, em que se dá a pandemia - não são sujeitos imaginários, mas, sim, sujeitos reais que se constituem e são constituídos com base em relações sociais pautadas nos tempos de hoje, com suas limitaçóes e faltas de acesso, potências e criaçóes.

O objetivo deste artigo é produzir uma reflexão acerca da temática das infâncias e das crianças no momento de pandemia, pensando os distanciamentos não apenas físicos, mas os abismos socioeconômicos e culturais que as crianças vivem, reforçados pelo sentimento e vivência de isolamento e sensação de restriçóes diversas. O intuito é possibilitar uma discussão sobre os modos como as infâncias e crianças têm sido tratadas, pensadas, pesquisadas, dialogadas e trabalhadas, criando rupturas em conceitos pré-estabelecidos e aberturas para situaçóes adversas, enfaticamente durante a pandemia, em áreas de interface e também na terapia ocupacional. Questiona-se se as resoluçóes colocadas, a partir das demandas surgidas com o cenário pandêmico atual, fazem uma análise sobre os modos como as crianças têm sido percebidas, ou se mantemos um discurso de exclusão e aniquilamento das diferenças, diversidades e pluralidades, e, consequentemente, das possibilidades diversas de infâncias.

Com uma população total de 210.147.1254 pessoas, segundo projeção do IBGE e em consonância com os dados do Observatório da Criança e do Adolescente ${ }^{1}$ do ano de 2019 (Fundação ABRINQ, 2019), o Brasil é um país com 65.600.982 milhões de crianças, ou seja, quase $1 / 3$ da população brasileira é constituído por crianças e adolescentes do zero aos 18 anos de idade. Deste total, estima-se que mais de 55 milhóes de crianças habitam as

${ }^{1}$ Link de acesso em: https://observatoriocrianca.org.br/cenario-infancia 
áreas urbanas, enquanto o restante habita as áreas rurais, provenientes principalmente das regiôes norte e nordeste do país.

Quanto à situação de vulnerabilidade, o Observatório da Criança e do Adolescente ${ }^{2}$ nos mostra que a proporção de crianças com menos de 14 anos identificada como pertencente às classes de rendimentos mais baixos é de 45,4\%, ou seja, 18.790 .798 crianças. Dados mais específicos, que nomeiam as situaçóes denominadas como desiguais, embora apontem, de forma geral, o Brasil como o $7^{\circ}$ país mais desigual do mundo (Programa das Naçóes Unidas para o Desenvolvimento, 2017), não foram encontradas, o que sugere uma lacuna quanto à qualificaçáo dos dados e recortes da porcentagem total de crianças que habitam as classes sociais mais baixas ou mesmo os locais mais periféricos, bem como a quantidade total de crianças que vivem em situaçóes de vulnerabilidades diversas.

De maneira geral, a constituição destes dados nos mostra que o Brasil é um país com um número elevado de crianças, constituindo uma população jovem, principalmente as que habitam as classes econômicas mais baixas, em áreas urbanas e rurais distintas, enfaticamente na região nordeste brasileira. Pensando as políticas e programas que se tem para as crianças no país, um dos principais pontos se refere às questóes escolares, enfaticamente às creches e escolas, entendidas como dever do Estado, na obrigatoriedade de oferta e demanda educacional, como a escola enquanto direito das crianças e familiares.

Considerando a escola como um dos principais locais voltados aos interesses das crianças e suas famílias, os dados referentes aos números de crianças matriculadas em creches no território brasileiro, em 2019, até os 3 anos de idade, era de 3.483 .230 milhóes; entre 4 e 5 anos, o número era de 4.744 .889 milhóes; já as crianças matriculadas no Ensino Fundamental somavam 26.923.730 milhôes; no Ensino Médio, não foi encontrado um número conciso de matrículas (dos 15 aos 17 anos).

Este dado é aqui relevante, pois, com base no entendimento de que a escola é o lugar da infância (lugar em que as crianças estão), temos hoje um total de mais de 60 milhóes de crianças sem aulas por conta do vírus da Covid-19 e das medidas restritivas; porém, o número de crianças fora da escola já era, antes da pandemia, bastante elevado (estima-se, aqui, um total de 30 milhóes de crianças, considerando o número de crianças matriculadas), o que nos provoca a pensar que o abandono escolar ou falta de acesso às escolas é um dado anterior à pandemia. De igual modo, a falta ou insuficiência de dados ou de outros indicativos de qualidade de vida da criança e o acesso aos direitos, implicando um distanciamento entre a vida da criança, a vida escolar e os direitos sociais, são também anteriores e que, com o cenário atual da Covid-19, parecem trazer à tona um debate antigo: de que crianças falamos e para qual crianças temos pensado açóes, programas e pesquisas?

Ao longo dos anos, pesquisadores nacionais e internacionais sobre os estudos das infâncias têm buscado dar visibilidade às crianças e às infâncias num âmbito social e cultural, refutando muitas das visóes universalizantes que englobam as formas de agir e pensar políticas com crianças, baseadas em visóes biologicistas e/ou desenvolvimentistas que as têm concebido no decorrer das décadas, em que as polarizaçôes se encontram entre uma infância "normal" ou "atípica", ou seja, numa concepção única de infância e de crianças que cabem ou náo dentro desse segmento (Pastore, 2020). As rupturas e

\footnotetext{
${ }^{2}$ Os dados trazidos se referem às crianças que vivem em famílias com rendimento de até $1 / 4$ ou $1 / 2$ salário-mínimo. Segundo o portal, esse número indica "a proporção e a quantidade da populaçáo total identificada nas classes de rendimento domiciliar mensal per capita de até meio e até um quarto de salário-mínimo" (2020), da qual o Nordeste é, novamente, a regiăo com maior índice de desigualdade.
} 
continuidades trazidas e escancaradas pela situação pandêmica têm possibilitado uma amplitude neste debate, fazendo-se questionar sobre as infâncias e suas diversidades, principalmente as desigualdades. Estaria o vírus trazendo modos de repensar as infâncias e, consequentemente, as crianças?

Falar sobre infâncias e crianças também na terapia ocupacional é estar em diálogo constante com suas histórias, contextos, culturas, questóes socioeconômicas, raciais, de gênero e geracional. Com as vulnerabilidades estampadas pela Covid-19, fica o questionamento: com quais crianças a terapia ocupacional tem atuado e sobre quais infâncias se tem pensado?

Nesse sentido, este texto é composto por um exercício de reflexão sobre a situação das crianças, a pandemia e suas consequências, ampliando um debate sobre as diversidades étnicas, culturais, raciais, de gênero, econômicas, socio-históricas, entre tantas outras possibilidades existentes entre as infâncias e seus contextos num diálogo com/na/para a terapia ocupacional. Pensar políticas públicas direcionadas ao momento atual é considerar as crianças em seus entornos e realidades, em tempos presentes e futuros, sendo o terapeuta ocupacional um dos profissionais capazes de mediar as relaçóes no âmbito das políticas sociais voltadas às crianças e infâncias.

\section{Metodologia}

Por ser um artigo pensado e produzido no momento latente da pandemia (maio de 2020), as referências bibliográficas sobre a temática ainda eram ainda incipientes. Buscou-se, em âmbito nacional, o levantamento de palestras, cursos, falas e publicaçóes, todas em forma online, que abordassem as questóes das crianças e a pandemia, principalmente nas áreas da educação e das ciências humanas. Na área da saúde, destacam-se as produçóes da Fiocruz, como "Covid 19 e a saúde da criança e do adolescente" e "observatório Covid-19". Na terapia ocupacional, alguns poucos documentos foram encontrados, valorizando principalmente os manuais produzidos pelo InformaSUS, plataforma digital da Universidade Federal de São Carlos, em prol da comunicação social no contexto da covid-19.

Com base em um breve levantamento bibliográfico realizado, com os descritores "crianças" e "pandemia", poucos artigos ou publicaçōes foram encontrados. $\mathrm{Na}$ base de dados Scielo, por exemplo, 17 artigos foram encontrados, nos quais os focos das publicaçóes variavam entre as rotinas familiares e as atividades das crianças, enfaticamente com crianças autistas, ou a saúde das crianças e adolescentes, ou sobre situaçóes de violência. Na base de dados Lilacs, dos 223 artigos, a maior parte focava na pandemia e na infecção pela Covid-19, não necessariamente em crianças; alguns poucos abordavam questóes voltadas às políticas públicas e direitos das crianças, pensando principalmente o momento pós-pandemia.

A busca mostrou que as crianças ainda são pouco citadas dentro das produçóes voltadas à Covid-19 e que novas formas de se buscar referências neste momento se tornam essenciais, principalmente nas plataformas digitais e nas redes sociais, como foi o caso dos cursos, webinar (seminários on-line), lives (palestras ou rodas de conversa realizadas em plataformas digitais ou em redes sociais, como Instagram ou Facebook), entre outros.

$\mathrm{O}$ intuito deste artigo, como um texto de reflexão, é apoiar o debate e discussóes sobre as crianças, infâncias e pandemia, fazendo-nos questionar qual o nosso papel, enquanto pensadores, críticos, profissionais, pesquisadores e estudiosos das infâncias e crianças no 
momento presente, além de nossa relação e implicação com a formulação de políticas sociais que pensem as crianças, e que sejam voltadas para elas e suas pluralidades.

\section{Infâncias e pandemia: há lugar para as crianças?}

Com o início da pandemia e as ações e medidas tomadas, as crianças têm sido colocadas dentro dos protocolos sanitários e de cuidados da população, em que o isolamento se faz primordial, principalmente com a ausência de aulas físicas. Pensando as especificidades das crianças, o questionamento que se faz é se poderíamos afirmar que tais protocolos e medidas restritivas têm considerado as crianças como sujeitos ativos, participantes e participativos, de direitos e políticos dentro dessas medidas: o que tem se pensado para as crianças e seu desenvolvimento? Para quais crianças temos olhado? De quais crianças falamos? Quais protocolos seguimos?

Muitas discussóes e eventos têm sido pensados sobre temáticas diversas, como gênero, sexualidade, racismo, branquitude, adoecimento mental, extermínio e necropolítica, confinamento, solidóes, questóes econômicas e políticas, entre outras. Porém, mesmo as crianças sendo permeadas também por todas essas questóes, elas geralmente são colocadas como externas a elas. Pensamos em transformaçóes de mundos, mas não consideramos as crianças dentro das inúmeras possibilidades, nem como interlocutoras dos diálogos anteriormente citados. Com ou sem pandemia, as crianças parecem não ter lugar no cenário da vida cotidiana, a não ser quando se tornam problema.

A infância passa a ser questionada e trazida à tona em diversos seminários, temas de palestras e debates on-line, principalmente em posicionamentos ligados à educação, quase como a ameaça de um sistema em que o humano é colocado em jogo, em disputa, dentro de um quadro político e econômico (Arroyo, 2020), mas a infância, enquanto categoria socialmente construída, com suas questôes e formulações pontuadas anteriormente, e que constitui a categoria etária e social na qual as crianças são integrantes, continua negada, soterrada e sem lugar evidente.

Arroyo (2020) nos provoca quando afirma que

quando a opressão é a regra, as perguntas são necessárias. [...]. Em tempos de interrogaçóes, deixe-nos interrogar. Que vidas estão sendo ameaçadas? Por que não trabalhamos nessa relação humana entre educação e vida? Porque não trabalhamos nem na educação nem para vida (Arroyo, 2020, s/p).

Ao compreender a educação e usá-la enquanto metáfora para práticas com crianças, que transcende o "lugar da criança" e a pensa em movimentos e contextos, compreendemos a criança, em sua formação, com base em demandas e realidades, possibilitando formas de ser e estar no mundo a partir de tempos reais e do aqui e agora. Crianças enquanto sujeitos deste tempo, em que se dá a pandemia; não são sujeitos imaginários, mas, sim, sujeitos reais que se constituem com base em relaçôes sociais pautadas nos tempos de hoje. Crianças consideradas cidadãs do futuro, mas que, no presente, parecem estar distantes ou afastadas dos espaços ditos comuns, ou coletivos, de uma vida em sociedade (Sarmento et al., 2007; Pereira, 2013).

Se antes havia a escola, para uma parte significativa dessas crianças, onde estão as crianças agora em que as aulas foram suspensas? É ingênuo da nossa parte, e talvez até 
perverso, achar que estão dentro de casa e que este período tem sido vivido de maneira igualitária para todas as crianças. Que crianças estão em casa? De que casa falamos?

Em nossas falas, açôes e pesquisas com crianças, durante a pandemia, temos considerado o confinamento seletivo? Ou ainda, a situaçáo das casas que as crianças habitam? Como ficam as crianças na geografia de quarentena, pensando uma arquitetura periférica que marca essas infâncias ou são marcadas por essas infâncias? $\mathrm{Ou}$, ainda, as crianças que estão nas ruas? Existe um lugar para essas crianças dentro dos confinamentos (Amore, 2020)?

Diante do cenário atual, as infâncias parecem confinadas em espaços que, de igual modo, parecem não permitirem sua existência, e as crianças, com seus corpos que não cabem em protocolos, de igual modo. Quando pensamos no confinamento, não são apenas corpos confinados, mas são aprisionamentos de experiências, de essências, de relaçóes, de toque, de trocas, de emoçóes, sentimentos, de experimentaçóes (Ghirardi, 2011; Nascimento, 2020).

Temos, na história da terapia ocupacional, açôes e pesquisas que têm se voltado, em sua grande maioria, às práticas desenvolvimentistas e de normalidade ou patologias, sem que recorram, na maior parte dos estudos, às abordagens socioculturais. Em tempos de pandemia, açóes têm sido pensadas quanto aos atendimentos, buscando principalmente cartilhas e manuais de como realizar determinado procedimento, bem como modos de brincar e brincadeiras para se fazer em determinados ambientes, na qual o público-alvo são os pais e familiares, que são as pessoas envolvidas no processo do brincar e ensinar brincadeiras, e menos as crianças de forma direta (Barba, 2020).

Alguns manuais de brincadeiras têm sido produzidos, principalmente na terapia ocupacional, pensando atividades para a rotinas das crianças e envolvimento dos pais nessa relação. Quase como guias voltados para as atividades em família, esses manuais têm circulado como possibilidade de entretenimento para as crianças, pensando o brincar como principal ocupação. Com base nesse cenário, algumas questôes são também colocadas: quais crianças têm os pais "disponíveis" para brincar com elas? Quais pais acessam os documentos propostos? Um dos documentos utilizados como guia para os pais, em tempos de brincar e pandemia e de favorecer a saúde da criança, é intitulado "como sobreviver à quarentena com crianças em casa?”, da Equipe Pé no Chão (2020). O título do e-book reforça, a meu ver, o estigma da criança-problema para além da pandemia, bem como do terapeuta ocupacional como profissional que direciona atividades para um público geral, sem diálogo com outras especificidades das crianças e mesmo dos seus ambientes. Devemos nos questionar se é possível as crianças praticarem yoga ou escutar sua música preferida, ou se as crianças sabem o que é isso ou se acessam tais estruturas.

Em um manual de brincadeiras ${ }^{3}$ para se fazer durante a pandemia, quais crianças estão sendo levadas em consideração? As ações para as crianças (algumas delas) se resumem a manuais, tal como protocolos? As questóes aqui levantadas não são sobre o conteúdo do material em si ou sobre discutir se as atividades são boas ou não. $\mathrm{O}$ ponto é pensar quais são as crianças que acessam esses materiais, quais têm a possibilidade de imprimir, ler e compreender cartilhas, ou mesmo acesso à internet e aos dispositivos de áudios e vídeos, e

\footnotetext{
${ }^{3}$ Alguns exemplos podem ser acessados nos links: https://www.yumpu.com/pt/document/read/62571466/cartilha-brincar ; https:/www.fmcsv.org.br/pt-BR/guia-atividades-familias-criancas-0-6-anos/\#criancas-ate-3anos ;

https://mcusercontent.com/43b7fb606a7e4daeb736694ef/files/cf9421cc-0c27-4ec6-be31-

bb76f83ccfb0/RotinaQuarentena_3_.pdf; http://www.institutosantosdumont.org.br/2020/05/19/covid-19-e-autismo-cartilhatraz-brincadeiras-e-dicas-para-quarentena/
} 
como temos entendido esse momento de pandemia também para as crianças: será que dar mais atividades, no intuito de preencher espaços ou lacunas ociosas, é pensar na criança em meio à pandemia?

A World Federation Of Occupational Therapists - WFOT (em português, Federação Mundial de Terapeutas Ocupacionais), desde $2010^{4}$, tem reforçado a necessidade de respeitar os valores, as crenças e a diversidade cultural, em consonância com aspectos sociais, psicológicos, biológicos, econômicos, políticos e espirituais de cada indivíduo e sua participação social, da qual as crianças deveriam estar conectadas e sendo consideradas. A pandemia parece provocar, como desafio, a organização e os modos de se pensar açóes e pesquisas que enfatizam a atuação nesses diferentes contextos culturais e propóe estratégias para um trabalho com crianças que seja pautado em suas realidades, considerando também os momentos em que o confinamento se torna presente. Torna-se urgente repensar os modos como temos problematizado as situaçóes e como as crianças e infâncias têm aparecido, questionadas e reinventadas.

Como observou Barros (2004, p. 95), "na ação é preciso que o técnico saiba redimensionar o próprio saber, saiba transitar em reaçôes de alteridades sociais e culturais". É necessário e urgente que a co-habitação das diferentes identidades se torne leitura de mundos possíveis, na qual os terapeutas ocupacionais tenham habilidades e capacidades para trabalhar as problemáticas que surgem nas sociedades e em demandas marcadas por desigualdades, das quais as crianças coexistem junto com a multiplicidade de infâncias (Barros et al., 2007; Pastore, 2020).

Este é o momento de questionar, mais do que nunca, a infância e os modos universalizantes que temos lidado com as crianças e com as práticas em/de terapia ocupacional com/para/sobre infâncias desde antes da pandemia e interrogar-nos: "que prática é esta que estamos fazendo e para qual projeto de mundo queremos seguir?”. Pensar a invisibilidade das infâncias e a negação de espaço para as diversas crianças se torna primordial.

\section{Vulnerabilidades sociais, diversidades e pandemia: diálogos entre terapia ocupacional e infâncias}

Em uma mesa sobre "grupos subjugados e vulnerabilidade das infâncias nas cidades" 5 , Caio Santo Amore, professor titular da faculdade de Arquitetura e Urbanismo da Universidade de São Paulo - USP, reflete sobre as condiçôes de violência, de moradia e de violações que têm permeado a constituição da cidade desde períodos anteriores, ou "desde que o Brasil foi inventado" (Amore, 2020), e reflete que foi preciso uma pandemia para nos fazer olhar para isso. Com uma concepção da sociedade capitalista, as condiçôes de sobrevivência das populaçóes e os modos como a vida tem sido organizada, ao longo dos anos, aponta para segregaçóes e violaçóes de direitos que têm conformado corpos e seus extermínios, dos quais as crianças têm sido moldadas dentro dessas configuraçóes, tal qual o cenário que constitui seus contextos.

Ao pensarmos a reclusão nos espaços domésticos e a espacialidade que se formou, ou reforçou, onde há uma mescla entre público e privado (Cohn, 2020), em que a vida das

\footnotetext{
${ }^{4}$ WFOT. Position Statements. Diversity and Culture. 2010

${ }^{5}$ Curso Infâncias em tempo de pandemia. Universidade Federal do ABC. Link de acesso:

http://cursos.ufabc.edu.br/digitalplural/inovacao-social-no-combate-a-pandemia-de-covid-19/cursos/infancias-na-pandemia/
} 
crianças também é permeada por esses acontecimentos e que levantam, enquanto questóes, a reconfiguração dos campos de estudos e os tempos do aqui e agora, há uma necessidade de ampliar discussóes sobre cuidado, direitos, vulnerabilidades e outras variáveis em que as crianças devem ser questionadas como sujeitos sociais e participantes de seus cotidianos, das modificaçóes impostas e que, embora não tenham sido colocadas como grupo de risco nessa pandemia, têm tido seus direitos negados, principalmente o de mobilidade e de participação (Muller, 2020; Ribeiro, 2020).

Costa (2020) relembra que, "além de tudo isso, não podemos nos esquecer de que crianças têm formas de compreender e comunicar sentimentos e pesares diferentes dos entendimentos dos adultos. É importante pensar estratégias de cuidado específicas para elas". Cohn (2020) e Ribeiro (2020) apontam para um debate sobre a pluralidade das infâncias e as condiçóes impostas pela pandemia, nas quais o confinamento, tal qual o adoecimento, não atinge as crianças de modos iguais: há uma diferenciação social das crianças, que marcam as pluralidades das experiências das infâncias, e que ressoa nas possibilidades de constituição e de vivenciar os períodos cotidianos e que, num diálogo com Costa, levanta questóes para a terapia ocupacional sobre os modos como temos trabalhado o entendimento das crianças e das infâncias no decorrer do nosso percurso profissional, sobretudo nas açóes desenvolvidas neste momento de pandemia.

Se produzimos o espaço e ele nos produz (Leitão, 2020), em tempos de confinamento e de afloramento das desigualdades, como têm sido produzidos os espaços para as crianças? $\mathrm{Na}$ terapia ocupacional, temos desenvolvido açôes em ambientes diversos: nos hospitais, como é o caso trazido por Silva et al. (2020) e o trabalho na UTI neonatal, na enfermaria pediátrica e no telemonitoramento; Sued (2020) discute sobre a importância do brincar em tempos de Covid-19, principalmente em um hospital na regiáo transamazônica; Ferigato (2020), dentro de um projeto interdepartamental e interdisciplinar, aborda sobre os cuidados nas ações de saúde mental junto às crianças e aos adolescentes; Barba (2020) reforça a importância do brincar em tempos de pandemia; o Laboratório LaFollia, da UFSCar, disponibilizou cartilhas com informaçóes sobre cuidados com autistas ante a pandemia (Agência FAPESP, 2020). Um dos pontos semelhantes, dentro das açóes, diz respeito aos atendimentos e ao cuidado das crianças a partir de instituiçóes de cuidado e pelo viés da saúde. Como agregar as múltiplas vulnerabilidades e diversidades que a pandemia tem trazido com as crianças que não estão nos serviços?

Os documentos produzidos pela Fio Cruz - Rio de Janeiro (Fundação Oswaldo Cruz, 2020) elencam questóes voltadas à saúde da criança e do adolescente no momento da pandemia, mas ainda de forma generalizada, sem especificar os grupos com quem se dialoga e como se pensa questóes de saúde e desigualdades sociais, num país pluriétnico como o Brasil; tampouco se distingue as variantes socioculturais ou societárias, invisibilizando, mais uma vez, as pluralidades e diferenças.

Por pluralidades de infâncias, podemos elencar alguns grupos de crianças: as crianças órfẫs dos casos letais de Covid-19; as crianças indígenas; as crianças quilombolas; as crianças ciganas; as crianças imigrantes; as crianças em situação de rua; as crianças vítimas de violências domésticas; as crianças imigrantes; as crianças nos acampamentos do MST; as crianças na vida, em diversas situaçóes, e todos os contextos possíveis (Miranda, 2020). Como pensar a "vulnerabilidade epidemiológica das crianças com a incidência da Covid-19 para a população infantil” sem levar em consideração todas essas questôes (Cohn, 2020)? 
Farias \& Leite (2021, p. 3) trazem para o debate que as "injustiças sociais são uma questão ética na sociedade contemporânea, pois o desejo de resolvê-las é uma opção política, tendo em vista que os recursos são existentes". Quando Santos (2020), em seu texto sobre "a cruel pedagogia do vírus", levanta os grupos vulneráveis atingidos diretamente pela Covid-19, e pontua, dentro destes grupos, as mulheres, os trabalhadores informais, os trabalhadores da rua, os sem-abrigo (ou em situação de rua), os moradores das periferias, os imigrantes e refugiados (em situaçóes distintas), os deficientes e, por fim, os idosos, acaba por deixar de fora, novamente, as crianças, que não aparecem em nenhum dos grupos citados, a não ser nas mulheres, quando essas sáo colocadas como máe e a sobrecarga do trabalho. Se pensarmos que as condiçóes para mudança são políticas, pensar as crianças e a posição que elas têm tomado ou ocupado durante esta pandemia (e, volto a repetir, não somente) é também ato político.

Falar sobre vulnerabilidades sociais, neste momento, é falar sobre a diversidade e pluralidade das infâncias das quais as crianças são sujeitos que coabitam os espaços, das implicaçóes encontradas nos diferentes locais e em suas estruturas, pelas realidades locais e pelos processos globais (Imoh, 2016). Com quais noçóes de vulnerabilidades a pandemia tem nos feito trabalhar e para quem temos direcionado nossas práticas, olhares e pesquisas? As crianças estariam, mais uma vez, apartadas desses cenários, ou têm sido sufocadas pelo silenciamento e as invisibilidades?

Enquanto terapeutas ocupacionais, cabe-nos perceber as vulnerabilidades e fragilidades, bem como as diferentes infâncias, e perceber os modos como a Covid-19 é vivenciada pelas diferentes crianças, revendo o lugar da pesquisa, da prática e do cuidado.

Permanece urgente e necessário pensar e repensar os modos como as crianças e suas realidades, entendidas a partir de contextos específicos, precisam integrar práticas diversas, entendendo a açáo das crianças e da comunidade como fundamentais no processo e que os saberes locais, culturais e sociais devem integrar o quadro das políticas, estudos e pesquisas no âmbito das infâncias e nas questóes sociais (Pastore, 2020, p. 140).

Ampliar uma discussão, neste momento presente, e buscar a pluralidade e diversidade das infâncias, dos seus contextos e as vulnerabilidades existentes são fatores fundamentais para se pensar modos de tornar as infâncias e as crianças visíveis e em práticas que se mobilizem a serem reais e, assim, transformadoras, estabelecendo um diálogo em que haja uma relação dialógica, descobrindo dimensóes e possibilidades da realidade, na qual as questóes técnicas são também produzidas e produtoras de histórias e culturas (Barros, 2004).

O projeto terapêutico, ou o projeto de vida, de pesquisa e de ações, tem que ter vida. Acolher as diversidades é a única possibilidade de transformar, em que "tornar a vida possível não é negar a realidade, mas, a partir da realidade dada, fazer outra coisa com ela" (Thebas, 2020).

\section{Pluralidades de infâncias e diversidade de crianças: diálogos intermitentes para além-pandemia}

As situações atuais e os modos como têm sido pensadas as práticas e pesquisas no momento da Covid-19 têm sido palco também de posicionamentos e direcionamentos da 
World Federation of Occupational Therapy - WFOT (World Federation of Occupational Therapy, 2020), de maneira global, e da Associação Brasileira de Terapeutas Ocupacionais (2020), de maneira nacional, compreendendo o papel do terapeuta ocupacional no enfrentamento das desigualdades e vulnerabilidades as quais o vírus tem nos exposto. Boaventura de Sousa Santos traz, também, que é momento de olharmos para as questóes presentes e buscarmos alternativas de como sairmos delas, ao compreender e nos chamar para as mudanças necessárias de paradigmas, cenários e modos de encarar as práticas e pesquisas que têm sido produzidas.

Pensar as crianças e as infâncias é pensar as cidades, as estruturas, os modos como os confinamentos têm sido feitos, ou náo, e para quem tem sido direcionado os protocolos e manuais. Não tem como pensar as infâncias sem as crianças que a permeiam, habitam, transformam e são transformadas. Modificamos a leitura de mundo ou ampliamos as lupas com as quais olhávamos determinados segmentos sociais?

As crianças, enquanto sujeitos de direitos, ativas e participativas, não têm sido consideradas dentro dos discursos e modus operandi. As sensaçóes, as emoçóes, os medos, as restriçóes... Pouco se tem olhado ou dialogado com as crianças em relaçóes a essas questóes. Produzir materiais, discussóes, temáticas, projetos e políticas que não levem em consideração as crianças e não as coloquem no cerne dos debates é continuar numa lógica excludente, em que as mudanças de paradigmas, conceitos e práticas continuam distantes. Pensar essas questóes se torna urgente e necessário náo apenas no que temos chamado de "pós-pandemia", mas em tempos do agora. Discutir e compreender as crianças e infâncias nas pluralidades e diversidades são modos de mediar as infinitas possibilidades de existência e resistência que permeiam os mundos infantis.

Neste momento, temos que repensar o "normal", os fazeres práticos e as pesquisas que temos direcionado, ou segregado, das crianças e das infâncias, bem como as definiçóes e noçóes que temos utilizado, enquanto terapeutas ocupacionais e no papel do cuidado que temos destinado. Precisamos rever o silêncio que carregamos quando negamos as diversidades e diferenças, compreendendo este silêncio também como produtor de misérias. Há uma oportunidade de fazer do agora um ato político, de mudanças e transformaçóes.

A pandemia tem nos colocado questóes reflexivas importantes, dentre elas, a de qual "barco" navegamos, enquanto metáfora dos caminhos que seguimos. A verdade é que náo estamos no mesmo barco e nunca estivemos no mesmo barco, e a questão que deve ser feita é: em que barco sairemos dessa?

Para cada travessia há sempre um momento em que não se está num lado nem de outro, em que não se é o que era nem o que será; pois, uma vez que são discriminados, o contíguo nunca os atinge. Fica-se em suspensão - pairando eternamente de permeio (Crapanzano, 2005, p. 378).

Com um Brasil plural e tão desigual, talvez seja o momento, na terapia ocupacional e além, de trabalhar as infâncias como travessias, em que a sugestão seja olhar para os estudos, práticas, contextos, teorias, saberes e fazeres sobre esses universos que nos levam de um lugar ao outro, abrindo caminho para que outros percursos sejam trilhados, dos quais as crianças e as infâncias náo sejam mais invisibilizadas, mas constituintes, transformadoras e possíveis. 


\section{Agradecimentos}

Aos antropólogos, sociólogos, pedagogos, geógrafos e historiadores das e para as infâncias, que têm me permitido navegar em outras travessias. Em especial, aos colegas pesquisadores do CRIAS/UFPB, com quem tenho trocado e aprendido tanto. Aos terapeutas ocupacionais que se propóem a pensar para além conceitos e navegar, também, em outros horizontes.

\section{Referências}

Agência FAPESP. (2020). UFSCar publica cartilha com informaçôes sobre cuidados com autistas ante Covid-19. Recuperado em julho de 2020, de http://agencia.fapesp.br/ufscar-publica-cartilhas-com-informacoessobre-cuidados-com-autistas-ante-covid-19/32926/

Associação Brasileira de Terapeutas Ocupacionais - ABRATO. (2020). Nota da ABRATO sobre a Portaria do Ministério da Saúde n. 639. Recuperado em junho de 2020, de https://www.facebook.com/abratonacional/

Amore, C. S. (2020). Quarentena dentro da quarentena: grupos subjugados e vulnerabilidade das infâncias na cidade. In Anais do $2^{\circ}$ Encontro do curso: Infâncias em tempos de pandemia. Santo André: UFABC.

Arroyo, M. (2020). Vidas das infâncias ameaçadas: quando a opressão é a regra. In Anais do $1^{\circ}$ Webnário: Infâncias e Educação Infantil em tempos de pandemia. Alagoas: UFAL.

Barba, P. C. S. D. (2020). Saúde da criança: o brincar em tempos de pandemia. InformaSUS UFSCar. Recuperado em 20 de julho de 2020, de https://www.informasus.ufscar.br/o-brincar-em-tempos-depandemia/

Barros, D. D. (2004). Terapia ocupacional social: o caminho se faz ao caminhar. Revista de Terapia Ocupacional da Universidade de São Paulo, 15(3), 90-97.

Barros, D. D., Almeida, M. C., \& Vecchia, T. (2007). Terapia ocupacional social: diversidade, cultura e saber técnico. Revista de Terapia Ocupacional da Universidade de São Paulo, 18(3), 128-134.

Cohn, C. (2020). Como fazer pesquisa com/sobre/para as crianças em tempos de pandemia do Covid-19? In Seminário Virtual. Prioridade Absoluta. Recuperado em 20 de julho de 2020, de https://prioridadeabsoluta.org.br/

Costa, J. D. (2020). Crianças com deficiência e seus cuidadores durante a pandemia. InformaSUS UFSCar. Recuperado em julho de 2020, de https://www.informasus.ufscar.br/criancas-com-deficiencia-e-seuscuidadores-durante-a-pandemia/

Crapanzano, V. (2005). Horizontes imaginativos e o aquém e além. Revista de Antropologia, 48(1), 363-384.

Equipe Pé no Chão. (2020). Como sobreviver à quarentena com crianças? InformaSUS UFSCar. Recuperado em julho de 2020, de https:/www.informasus.ufscar.br/o-brincar-em-tempos-depandemia/

Farias, M. N., \& Leite, J. D. (2021). Vulnerabilidade social e Covid-19: consideraçôes a partir da terapia ocupacional social. Cadernos Brasileiros de Terapia Ocupacional, 29, e2099. http://dx.doi.org/10.1590/2526-8910.ctoEN2099.

Ferigato, S. (2020). Saúde Mental e Covid-19: narrativas do cuidado infanto-juvenil. Recuperado em julho de 2020, de https://www.informasus.ufscar.br/saude-mental-e-covid-19-narrativas-do-cuidadoinfantojuvenil/

Fundação ABRINQ - Observatório da Criança e do Adolescente (2019). Estratificação da população estimada pelo IBGE segundo faixas etárias. Disponível em: https://observatoriocrianca.org.br/cenarioinfancia/temas/populacao/1048-estratificacao-da-populacao-estimada-pelo-ibge-segundo-faixasetarias?filters $=1,1627$

Fundação Oswaldo Cruz - Fiocruz (2020). Documentos produzidos pelo Observatório Covid-19. Comunicação e informação. Informação para ação. Brasil: Portal Fiocruz. Recuperado em julho de 2020, de http://portal.fiocruz.br/documento-covid-2020. 
Ghirardi, M. I. G. (2011). Percursos de pesquisa e estratégias de ensino no campo da assistência em terapia ocupacional. Revista de Terapia Ocupacional da Universidade de São Paulo, 22(3), 216-220. https://doi.org/10.11606/issn.2238-6149.v22i3p216-220.

Imoh, T. A. (2016). From the singular to the plural: exploring diversities in contemporary childhoods in sub-Saharan Africa. Childhood, 23(3), 455-468. http://dx.doi.org/10.1177/0907568216648746.

Leitão, K. (2020). Quarentena dentro da quarentena: grupos subjugados e vulnerabilidade das infâncias na cidade. In Anais do $2^{\circ}$ Encontro do curso: Infâncias em tempos de pandemia. Santo André: UFABC.

Miranda, H. (2020). Como fazer pesquisa com/sobre/para as crianças em tempos de pandemia do Covid-19? In Seminário Virtual. Prioridade absoluta. Recuperado em junho de 2020, de https://prioridadeabsoluta.org.br/.

Muller, F. (2020). Mobilidade urbana de crianças. In Anais do Encontro virtual Grupo de Pesquisa Criança, Sociedade e Cultura. Alagoas: UFPB.

Nascimento, M. L. B. P. (2020). Invisibilidade e participação: desafios dos estudos da infância. In Anais do Encontro virtual Grupo de Pesquisa Criança, Sociedade e Cultura. Alagoas: UFPB.

Pastore, M. N. (2020). Brincar-brinquedo, criar-fazendo: pluriversos de infâncias e crianças desde o sul de Moçambique. (Tese de doutorado). Universidade Federal de São Carlos, São Carlos. Recuperado em junho de 2020, de https://repositorio.ufscar.br/handle/ufscar/12307

Pereira, M. A. (2013). Movimentos a favor da infância. Brinque, conviva, compartilhe. In Memórias do futuro: olhares da infância brasileira. Ministério da cultura. Recuperado em maio de 2020, de http://memoriasdofuturo.com.br.

Programa das Naçóes Unidas para o Desenvolvimento - PNUD. (2017). Relatório Anual 2017. Brasília: PNUD.

Ribeiro, F. B. (2020). Como fazer pesquisa com/sobre/para as crianças em tempos de pandemia do Covid19? In Seminário Virtual. Prioridade absoluta. Recuperado em junho de 2020, de https://prioridadeabsoluta.org.br/

Santos, B. S. (2020). A cruel pedagogia do vírus. Coimbra: Edições Almeida.

Sarmento, M., Fernandes, N., \& Tomás, C. (2007). Políticas públicas e participação infantil. Educação Sociedade \& Culturas, (25), 183-206.

Silva, M. R., Silva, R. C., Rabelo, H. D., \& Vinhas, B. C. V. (2020). A Terapia Ocupacional pediátrica brasileira diante da pandemia da COVID-19: reformulando a prática profissional. Revista Interinstitucional Brasileira de Terapia Ocupacional, 4(3), 422-437. http://dx.doi.org/10.47222/25263544.rbto34171.

Sued, K. (2020). A importância do brincar em tempos de Covid-19. RedePará. Recuperado em julho de 2020, de https://redepara.com.br/Noticia/213888/a-importancia-do-brincar-em-tempos-de-covid-19

Thebas, C. (2020). Saúde integral em tempos de pandemia, impactos para as infâncias. In Anais do $4^{o}$ encontro do curso: Infâncias em tempos de pandemia. Santo André: UFABC.

World Federation of Occupational Therapy - WFOT. (2020). Covid-19 pandemic: Information and Resources for Occupational Therapists. Recuperado em junho de 2020, de https://www.wfot.org/covid-19information-and-resources-for-occupational-therapists

Autora para correspondência

Marina Di Napoli Pastore

E-mail: marinan.pastore@gmail.com

\section{Editora de seçáo}

Profa. Dra. Ana Paula Serrata Malfitano 